\title{
A Word-Association Study in Greek and the Concept of the Syntagmatic-Paradigmatic Shift
}

\author{
Marina Mattheoudakis \\ Aristotle University of Thessaloniki \\ marmat@enl.auth.gr
}

\begin{abstract}
This paper examines the developmental shift of response type through a qualitative study of word associations in Greek. In particular, it tests whether the associations produced by Greek speakers confirm findings of similar studies in other languages with respect to the syntagmaticparadigmatic shift. To this aim, a translated version of the Kent-Rosanoff test was administered to both adults and children who were native speakers of Greek. The findings of this study do not provide support for the concept of the syntagmatic-paradigmatic shift, as they indicate a predominance of paradigmatic associations in children's responses and a majority of syntagmatic associations in adults' responses. The paper discusses the concept of the syntagmatic-paradigmatic shift and suggests the need for further research in word associations in Greek but also in other languages.
\end{abstract}

\section{Keywords}

mental lexicon, word associations, syntagmatic-paradigmatic shift, Kent-Rosanoff test, Greek

\section{Introduction}

Word associations are often used as a method of exploring semantic representations and lexical access, and word association tests (WAT) have proven to be an experimental tool—for both psychology and linguistics — which is effective and easy to administer and score. At the beginning of the $20^{\text {th }}$ century, research using word association tests led to the compilation of various norming lists (Kent \& Rosanoff 1910; Woodrow \& Lowell 1916, etc.), whereas in the 1960 s and 1970 s psychologists used word association tests to study the cognitive development of L1 children (Szalay, Windle \& Lysne 1970).

After the 1960s, researchers' interest with respect to word associations turned to the classification of associations and to the development of theories accounting for such classifications. Studies conducted at that time attempted to classify and compare patterns of response type given by native speaking 
adults and children to a list of common prompt words (Brown \& Berko 1960; Ervin 1961; Palermo 1971); the classification of their responses was based on the syntagmatic-paradigmatic-clang distinction. Paradigmatic responses belong to the same grammatical category as the stimulus words, e.g., toothmouth, whereas syntagmatic associations usually belong to a different grammatical category from the stimulus words and are found in the same sentence or phrase, e.g., sit - chair; both paradigmatic and syntagmatic responses are semantically related to the prompt word. Clang associations, however, are heavily influenced by the form of the stimulus words, e.g., royal-loyal. A consistent finding of those studies was that adults' responses were predominantly paradigmatic, whereas younger children produced mostly syntagmatic responses as well as a large number of clang associations. The changes observed in children's responses as they grew older were referred to as the syntagmaticparadigmatic shift. The syntagmatic-paradigmatic shift was believed to be related to children's lexical or cognitive development.

More recently, word association tests have been used in linguistic research as word associations are believed to reflect basic characteristics of the organization of the L1 and L2 mental lexicons. In this respect, word association tests can help us expand our basic understanding of the representational properties of the mental lexicon and the access routes which are available to the native and the non-native speaker.

Most models of spoken and written recognition view lexical access as a process of matching the perceptual signal (spoken or written) to potential lexical candidates (Marslen-Wilson 1987; Goldinger, Palmeri, \& Pisoni 1992; Marslen-Wilson, Moss \& van Halen 1996). The competitive activation of those candidates, modulated by the extent of similarity to the perceptual signal and other lexical-representational factors, yields a single word percept (Carreiras et al. 2008). One of the most robust representational properties of lexical forms that influence this matching process is lexical frequency. By 'lexical frequency' we refer to the observation that speed and accuracy of recognition of common words are higher than those of less frequent words (Forster and Chambers 1973, inter alia).

As regards the organization of the mental lexicon, this consists of lexical items represented in terms of form and meaning. To date, different models of the organization of the mental lexicon have been put forward. Early research on malapropisms in L1 by Fay and Cutler (1977) suggested a phonological arrangement of words and postulated the existence of a lexicon which is accessed by two different networks, a phonological and a semantic one. Comprehension and production processes are based on a unidirectional mapping between meaning and sound; i.e. a mapping from sound to meaning for 
comprehension and from meaning to sound for production. More recently, associative research has suggested that phonological form may be the early organizing principle in the L1 lexicon. This is based on the early formation of clang associations before the production of syntagmatic or paradigmatic ones which are indicative of the increasing role of meaning-based associations (Wolter 2001; Namei 2004). Along these lines, Schmitt (2000: 123) claims that categorization of new words in L1 is initially based on "perceptional similarity (particularly shape similarity)," whereas at later stages it shifts to semantic relatedness (in particular coordinate relationships). Physiological facts about how neurons work also have suggested that lexical items are organized into networks. This "cobweb-like" organization of the mental lexicon is evident even at a relatively early age (Aitchison 1987). When it comes to new lexical items, children are able to incorporate them in their mental network, but these new words form looser connections to one another and to the items that were present before their arrival than the items already present in children's mental lexicon (Gósy \& Kovács 2002).

Speakers of a language are assumed to have the following information for lexical representations: phonological form, internal word structure, and where applicable, subcategorization features, as well as other morphological features, e.g., gender, syntactic category, and semantic features, including argument structure (Kehayia 1997). Research on the mental lexicon aims to establish generalizations about language representation and processing that would hold across languages and would thus be revealing of human mental organization. However, we know that the phonological, morphological, syntactic, and semantic characteristics of individual languages make particular demands on language processing (Libben \& Jarema 2002). Studies of processing in bilinguals and cross-linguistic studies have actually indicated that representations and processes "may not be generalizable to analogous structures in other languages without a consideration of language-specific morphological properties" (Jarema et al. 2002, p. 736).

The present study aims to explore Greek native speakers' response patterns to word association tests as these are expected to shed light on the structure of the Greek mental lexicon. As Greek is typologically different from English, the language in which most word association studies have been conducted, results of word association tests in Greek with L1 children and adult participants may indicate differences between the Greek and English response patterns, and therefore differences between the Greek and English mental lexicons.

Studies in the Greek mental lexicon have attempted to address several issues relating to lexical representation and lexical access: the effect of specific semantic features [ \pm concrete] of Greek nouns on reaction times during word 
recognition (Manouilidou \& Kehayia 2004), the effect of the internal morphological structure of compounds on lexical access (Kehayia et al. 1999), the relationship between morphological regularity and form during lexical processing (Tsapkini, Jarema \& Kehayia 2002), and the effect of input modality in lexical processing (Tsapkini, Jarema \& Kehayia 2004), to mention just a few. To our knowledge, though, research has not as yet explored word association norms in Greek in order to investigate the organization of the Greek mental lexicon or any differences between the mental lexicon of Greek children and that of Greek adults.

\section{Studies in Word Associations}

Ervin's study (1961) is one of the earliest studies which aimed to compare types of responses given in word association tests by native children and adults. Her results indicated that stimulus words which elicit mostly paradigmatic responses in adults tend to elicit more syntagmatic responses in children. Additionally, her results showed that paradigmatic responses increased as children grew older and advanced to higher school grades, while clang associates decreased. Ervin suggested that children tend to produce syntagmatic associations for words that they have not encountered frequently and in a variety of contexts. On the other hand, prompt words will tend to elicit paradigmatic responses when they have acquired contextual independence, i.e., when children possess adequate knowledge of their contextual variety. Ervin also observed that the form class of the stimulus words influences the type of association produced. Thus, nouns produce mostly paradigmatic associations while adverbs syntagmatic; verbs and adjectives fall in between.

Brown and Berko's study at about the same time (1960) produced similar results: an increase in paradigmatic responses as children grew up and an earlier shift for nouns. Their explanation for this shift in responses was related to children's greater awareness of the different parts of speech as they grew up and thus to their syntactic development.

Some years later Entwisle's research (1966) confirmed the results obtained by Ervin (1961) and Brown and Berko (1960) and further suggested that as a child's exposure to language increases, the type of association changes moving from nonsensical to early syntagmatic, to paradigmatic and finally to late syntagmatic (1966). By late syntagmatic or 'late syntactic', Entwisle meant associations which indicated a "more flexible and richer understanding of a concept" (p.74).

An alternative interpretation of the syntagmatic-paradigmatic shift was proposed by McNeill (1970) who suggested that the syntagmatic-paradigmatic 
shift occurs at the age of 6 to 8 years when semantic consolidation takes place. According to McNeill, a lexical item can be specified by various semantic features; when a child learns a new word, s/he does not acquire all the semantic properties associated with the particular word. Semantic development is a gradual and progressive process.

More recently, a study by Cronin (2002) examined the relation between the shift of response phenomenon and children's reading acquisition. Her results indicated that as children acquired reading, their paradigmatic responses became more frequent, the syntagmatic ones remained constant, while clang and other unclassifiable responses diminished. Thus, Cronin suggested that the term 'syntagmatic-paradigmatic shift' cannot adequately express the change observed in the responses of young children and further proposed that increased paradigmatic responses may be attributed to reading acquisition, which in turn is related to children's greater understanding of words (Cronin 2002).

The word association tests used with native speakers usually include highly frequent words which have been found to elicit a limited set of fairly predictable responses. When lower frequency words have been used as stimuli, the pattern of responses changes and native speakers have been found to provide a much greater diversity of responses and several "childlike" or "nonnativelike" ones (Postman 1970; Stolz \& Tiffany 1972). Statistical analyses conducted by Postman indicated that as the frequency of the stimulus words decreased, the total number of different responses increased. Wolter (2001) questioned the ability of word-frequency ratings to provide us with a description of the structure of mental lexicon; his study actually indicated that an important factor that underlies the organization of words in the mental lexicon is the depth of word knowledge, in other words the degree to which the speaker (L1 or L2) knows a word. Words that are better known by native speakers elicit mostly paradigmatic responses; words that are moderately known elicit both paradigmatic and syntagmatic ones and words that are not known elicit clang responses.

Recent studies used word association tests with both L1 and L2 speakers in order to compare the L1 and L2 mental lexicons (Meara 1982; Söderman 1993; Wolter 2001; Namei 2004). Early studies indicated that the organization of the L1 mental lexicon is mainly semantic, while the L2 mental lexicon is initially mainly phonologically organized (Meara 1982); this, according to researchers, indicated a less profound lexical knowledge for L2 learners. More recently, Wolter (2001) carried out a study into the structure of the L1 and L2 mental lexicons and concluded that phonology in both L1 and L2 appears to be more important for words that are not very well known; as words become 
better known, semantic organization takes precedence. Namei's research in L1 and L2 word associations similarly indicates that both the L1 and the L2 mental lexicons contain phonologically-based associations, as "phonological organization is a primary acquisition feature of every individual word" (2004: 363). In particular, words that are just being learned will elicit clang associations regardless of speakers' level of proficiency, whether in the L1 or the L2; as words become better learned, they acquire syntactic or paradigmatic bonds with other words.

Regarding the concept of the syntagmatic-paradigmatic shift, the results of those studies indicated that this is actually a misnomer as even adult native speakers were found to produce a large number of syntagmatic associations and even some clang and unclassifiable responses when they were presented with uncommon, infrequent words. In fact, the results of the above studies were consistent in suggesting that the patterns of response type to prompt words in both L1 and L2 are related not only to the age or the L2 proficiency of the participants - when talking about foreign language learners - but also to their familiarity with the particular prompt words.

Söderman (1993) concluded that lexical development is a slow, lifelong process and does not affect simultaneously all the words of the mental lexicon. Thus, the syntagmatic-paradigmatic shift does not occur at the same time for all the words in the mental lexicon but indicates increased knowledge of the words tested. Wolter (2001) proposed a developmental model for the mental lexicon - for both L1 and L2 - in which individual words are known to various degrees depending on participants' exposure to them. Such a model can account for the results of word association tests with both native and nonnative adult speakers as well as for the differences between native speaking children and adults. More recently, Namei (2004) proposed a new wordknowledge continuum framework which aims to show what happens to a word as it moves along the continuum and acquires more precise meanings. Such a continuum emphasizes that the syntagmatic-paradigmatic shift takes place at a different time for each individual word.

In a more recent study of the influence of word class on L1 and L2 word associations, Nissen and Henriksen (2006) found that L1 Danish speakers tend to produce a predominance of syntagmatic responses. Their results indicated that another factor which seems to influence the structure of the mental lexicon is the grammatical class of words. In their study, nouns were found to elicit mostly paradigmatic associations, whereas verbs and adjectives elicited mostly syntagmatic responses. This finding is at variance with previous studies (Söderman 1993; Wolter 2001) and points to the need for reconsidering the concept of the syntagmatic-paradigmatic shift as an indication of lexical and cognitive development. 


\section{Aims and Hypotheses}

Most studies of response type in word association tests have been conducted in English. As a result, there is quite a large number of English association norms referred to in literature, and some of them are also available in published form (Kent \& Rosanoff 1910; Palermo \& Jenkins 1964; Postman \& Keppel 1970, etc.). Postman and Keppel's publication (1970) also includes lists of norms in French and German based on the responses given by native speakers of these languages to the Kent-Rosanoff list, which was translated into French and German, respectively. Other normative studies which used translations of the Kent-Rosanoff list were those of Italian psychologists (Rosenzweig 1970). Comparative studies between norms in English, French, German, and Italian as well as between associations obtained in the US, Australia and England have also been carried out (ibid.).

With respect to Greek, Maniou-Vakali, Sygollitou, and Kostaridou-Efkleidi (1984) produced a list of association norms in this language. Specifically, they conducted a quantitative analysis of word associations in Greek and examined the frequency of particular responses and the strength of association between stimulus and response. However, their study was limited only to noun prompts and did not provide a qualitative analysis of the types of associations given, i.e., information about the grammatical relation between stimulus and response. More recently, Joannopoulou (2007) studied the associations produced by Greek adult speakers to 50 highly frequent prompt words in English and their translation equivalents in Greek in order to compare the L1 and L2 mental lexicons. The researcher concluded that the two mental lexicons were similarly organized as the proportions of syntagmatic, paradigmatic, and clang responses provided by the Greek participants were very similar in L1 (Greek) and L2 (English).

The present study focuses on the use of word association tests for the investigation of the properties of the links between words in the Greek L1 mental lexicon and, more particularly, for the examination of the concept of the syntagmatic-paradigmatic shift in Greek. We will discuss the syntagmaticparadigmatic shift as this has been observed in other languages, and we will attempt a discussion about the organization of the Greek mental lexicon based on the evidence obtained from our tests. A Greek word association study is expected to add to our understanding of the issues raised in previous research, as Greek morphology and syntax are quite different from the English morphosyntax, and such differences are expected to influence Greek speakers' responses to the word association test.

To this aim, we will classify and compare the patterns of response type produced by children and adult native speakers (NS) of Greek to a translated 
version of the Kent-Rosanoff test. Previous research suggests that the adult mental lexicon is predominantly paradigmatically structured, whereas children produce mostly syntagmatic responses. Therefore, Greek adult speakers are expected to produce more paradigmatic than syntagmatic responses, whereas children are expected to provide a larger proportion of syntagmatic than paradigmatic associations, as well as a large number of clang associations.

The hypotheses of this study are:

(1) the proportion of paradigmatic responses produced by adults will be larger than the proportion of syntagmatic responses;

(2) the proportion of syntagmatic responses in children will be larger than the proportion of paradigmatic responses;

(3) the proportion of syntagmatic responses in children will be larger than the proportion of syntagmatic responses in adults;

(4) the proportion of paradigmatic responses produced by adults will be larger than the proportion of paradigmatic responses produced by children;

(5) children will produce more clang and nonsensical responses than adults.

Thus, the results of our study are expected to confirm the syntagmaticparadigmatic shift - or, as it has been called, the developmental shift in response type.

\section{The Greek Language}

Greek is a fully inflected language: nouns and adjectives are inflected to indicate number (singular or plural), gender (masculine, feminine, or neuter) and case (nominative, genitive, accusative, and vocative); verbs inflect to indicate person, tense, mood, voice, aspect and number. Greek is also a synthetic language with a high degree of fusion in the marking of grammatical categories. Such morphological differences between languages intersect with syntactic differences as well. Greek is a pro-drop language, as opposed to English, for example, and due to nominal and verbal inflection, word order in Greek is relatively free with SVO, VSO and other word orders as frequent alternatives. With respect to noun phrases, adjectives precede nouns (for

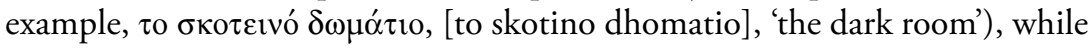

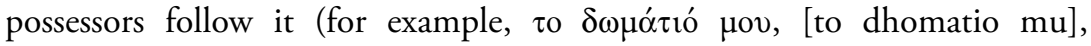
'my room'); the opposite order is possible as a marked alternative in both cases (Joseph \& Philippaki-Warburton 1987/1989; Holton, Mackridge \& Philippaki-Warburton 1999). 
Due to those morpho-syntactic differences between the two languages, comparisons between Greek and English speakers' patterns of responses are expected to add to or question the generalizability of previous research findings.

\section{Method}

\subsection{Participants}

There were two groups of participants in this study: The first one included 100 Greek native children between 7 and 8 years old, pupils in the second grade of primary school. Three primary schools from the wider area of Thessaloniki (Northern Greece) were randomly selected for the purpose of this study. Permission for children's participation was granted both by their parents and the Regional Educational Directorate. The second group included $100 \mathrm{stu}-$ dents of the Department of English Language and Literature, Aristotle University of Thessaloniki. All of the students were native speakers of Greek and studied English as a foreign language in Greece. The age range of the participants was from 18 to 23 years old, with a heavy concentration between the ages of 18 and 21. Participation was voluntary.

\subsection{Elicitation instrument}

Several word association studies in English and other languages used the original Kent-Rosanoff list or a translated version of this test. For the aims of the present study the Kent-Rosanoff test was translated and adapted into Greek (Appendix I). A number of reasons dictated the selection of this particular list of words. First of all, this is a standard word association test for which there are well-documented response norms; these cover different ages (children, adolescents, and adults), languages (English, French, German, Italian), and geographical areas (Postman \& Keppel 1970). It has been found that the response patterns produced by adult native speakers to the Kent-Rosanoff prompt words are fairly stable. This will allow us to compare patterns of responses between Greek speakers and native speakers of other languages who took the same test and thus attribute any possible differences found to differences in the structure of Greek speakers' mental lexicon and/or to the structure of the Greek language. Another reason which influenced our choice is the fact that the Kent-Rosanoff list consists of highly common words. This means 
that most of the prompt words are expected to be familiar and thus elicit responses even from the group of young children participating in our study.

The Kent-Rosanoff test consists of 100 frequently occurring English words which are emotionally neutral. As already stated, the words included in the original list were translated and adapted into Greek; by "adaptation" we mean decisions made with regard to (a) the part of speech of the translated item, and (b) the stylistic register of the corresponding translated item. Word frequency as well as children's familiarity with those words also influenced our final decisions and choices. In particular, children were expected to be familiar with words that they already had encountered in their textbooks; in fact, $93 \%$ of the stimulus words were found in the textbooks of their grade. Stimulus words not found in those textbooks were the following; ouiski ('whiskey'), sfiri ('hammer'), trachis ('rough'), politis ('citizen'), anesi ('comfort'), mnimi ('memory'), agrotospito ('cottage'), dhikeosini ('justice'). However, four of them, namely, politis ('citizen'), anesi ('comfort'), mnimi ('memory'), and dhikeosini ('justice') feature among the 5,000 most frequent Greek lexical items. Although the two lists are not matched for frequency, efforts were made, whenever possible, to choose translation equivalents that would match the original items in both register and frequency. To this aim, we made use of frequency lists in both English and Greek ${ }^{1}$. Frequency was calculated for both the original English test and the Greek translated version. For the English test, the mean frequency of items was $1,803.83$, the median 961.5, and the range 11,957. The respective values for the Greek test were 3,250.81 (mean), 2,531.5 (median), and 11,869 (range). Differences in those values are mainly due to differences between the two corpora. The Collins WordBanks online is a corpus of more than 500,000,000 words and contains a wide range of texts from various sources, both written and spoken; the Hellenic National Corpus is much smaller - it contains about $48,000,000$ words - but this is a corpus of written texts only ${ }^{2}$.

The translation of several of the prompt words into Greek presented various problems (cf. Entwisle, Forsyth \& Muuss 1964; Rosenzweig 1970; Joannopoulou 2007). In a number of cases, the word class of the English prompt word is ambiguous. For example, wish, command, sleep, comfort, whistle, and dream can serve as either nouns or verbs. Such grammatical ambiguity

\footnotetext{
${ }^{1}$ Frequency information for English and Greek prompt words was retrieved from the Collins WordBanks online (http://wordbanks.harpercollins.co.uk) and the Hellenic National Corpus (www.ilsp.gr), respectively.

${ }^{2}$ In future, measurements on spoken language corpora should be included so as to establish more reliable frequency counts.
} 
is not possible in Greek and, therefore, the particular stimuli would have to be translated either as nouns or as verbs. An attempt was made to represent both classes in a balanced way. In addition, some of the prompt words in the list are polysemous, (e.g. hard), and their translation into Greek would have to be based on an ad hoc decision. In other cases, however, the semantic ambiguity is actually related to the grammatical ambiguity of the prompt word, so the choice of the translation equivalent into Greek was actually related to our decision as to which grammatical category would be represented. Thus, for example, light would be translated as 'elafris', if we decided to use it as an adjective, or as 'fos' if we chose to use it as a noun.

Words like swift or cottage presented us with a different kind of problem. For example, the adjective swift has various translation equivalents in Greek, namely, 'sveltos', 'tachis', 'grigoros'. The first two are stylistically marked: 'sveltos' is colloquial and 'tachis' is used in formal registers and has quite a restricted range of use; so, we opted for the third translation which is neutral and more frequent. With respect to the word cottage, the closest translation equivalent in Greek would be 'eksochiko spiti' ('country house'). In order to avoid the use of a lexical phrase, we chose instead the compound 'agrotospito' (farmhouse).

\subsection{Data collection procedure}

Participants were instructed to provide a single response to each of the 100 words. Single responses were preferred to multiple responses as we were interested in the association of the primary responses only; this also helped us avoid any chaining effects. Furthermore, providing multiple responses would be a laborious task for young children. All participants, children and adults alike, performed the test using the written mode, as it is both easier and quicker to administer to large groups of participants than the aural-oral one.

The norms were collected in a classroom setting and the test was administered to small groups of students each time (20-30). Attached to the test was a cover sheet which required participants to provide their age, also giving instructions for a written word association test. Children's instructions were simplified and further clarifications were provided orally to them at the beginning of the session (Appendix I). Both groups of participants were presented with the same examples prior to the test, but children were encouraged to ask questions for further clarification. The examples included four stimuli (a noun, an adjective, a verb, and an adverb) followed by a paradigmatic and a syntagmatic association each. Participants were also warned that no questions would be allowed once they began taking the test. The order of the words was randomly determined. The adult participants were given 20-25 minutes to 
complete the task, whereas children were allowed to take 50-60 minutes. This time extension for children was a necessary provision, as their writing skills were quite limited, and thus they needed more time to produce their answers in writing. During a pilot study, several children complained about the length of the task and some of them did not even manage to complete it; thus, it was decided to split the time required into two 30-minute sessions and allow children to have a break of 10 minutes in-between. Despite this difficulty, we decided to opt for the written rather than the oral test mode, for adults as well as for children, given that orally presented prompt words might elicit a higher proportion of paradigmatic responses when compared to visually presented words (Cramer 1968).

\subsection{Classification of responses}

On the basis of the semantico-grammatical relation between prompt words and responses, all associations elicited by the participants were classified as "paradigmatic", "syntagmatic", "clang", or "other". In cases where participants could not produce a response, a classification of "no response" was given. Usually a response is classified as paradigmatic or syntagmatic on the basis of whether or not it belongs to the same grammatical category as the prompt word. In many cases this is a straightforward decision and classification creates no problems to the researcher. However, as becomes clear below, the distinction is not always easy to make. Meara (1982), Söderman (1993) and, more recently, Fitzpatrick (2006) have similarly commented on the difficulty of deciding whether an association is paradigmatic or syntagmatic (see also Joannopoulou 2007). In order to address this problem, Fitzpatrick employed a system of categories and subcategories, and the classification of her participants' responses was made according to information elicited from each participant during an interview. Clearly, taking into consideration participants' own perspective is expected to clarify links between words unambiguously. However, such a method might prove ineffective with children. Also, as the number of prompt words is quite large, interviews might be impractical and tiresome even for adult participants.

In our study, response categories were defined as follows, based on the definitions given by Söderman (1993) and Wolter (2001):

Paradigmatic: A response was classified as paradigmatic when it belonged to the same word class as the prompt word and showed a clear semantic connection to it (e.g., trapezi ('table') - karekla ('chair'); see also Nissen \& Henriksen 2006). Judgements about semantic relatedness were based on the following criteria: (a) both stimulus and response should share at least part of their 
meaning, and (b) they should normally occur in the same contexts (cf. Meara 2009). However, in Greek, the sequence of two nouns where the first one is in the nominative case and the second one in the genitive, is actually a noun phrase, e.g., fos - imeras, literally meaning 'light of the day'. In such cases, although both stimulus and response are nouns, their combination in a phrase expresses a clear sequential relationship and is thus classified as a syntagmatic association (cf. Hirsh \& Tree 2001). Similarly, a stimulus and a response which belong to the same word class but represent a collocational phrase or an appositional compound (see Plag 2003) have been classified as a syntagmatic association (e.g., pedhi ('child') - violi ('violin'), an idiomatic expression denoting a difficult and unreliable person).

Syntagmatic: A response was classified as syntagmatic in the following cases:

(a) when it belonged to a different word class than the prompt word and was sequentially related to it (e.g., sovaro ('serious') - provlima ('problem'));

(b) when it was from the same word class as the prompt word and demonstrated a sequential relation to it: e.g., mnimi (noun in the nominative case) - elefanta (noun in the genitive case), literally meaning 'memory of an elephant';

(c) when it belonged to the same word class as the prompt word and represented a collocational phrase or an appositional compound, e.g., pedhi (n.) - thavma (n.) ('child'- 'prodigy').

Clang: Responses that are influenced by the form of the prompt word (e.g. po'litis (n.) - poli'tis (n.) meaning 'citizen' and 'salesman', respectively) were classified as "clang responses".

Other: Responses that did not bear an obvious semantic relation to the prompt word, as well as those that were simply a different form of the prompt word (e.g., ipnos-dheka ('sleep'-ten'), ijia-lojia ('health'-'words'), and dhiataji dhiatazo ('command'-'to command')) were assigned to this category.

Although every effort was made to be consistent in the categorization of responses as described above, the distinction between syntagmatic and paradigmatic associations proved to be difficult. As both prompt words and responses are decontextualized, it is not possible to know the context that participants have in mind when they associate and thus determine with any certainty the type of association produced.

\subsection{Data analysis and results}

The first part of the analysis will report on the relative distribution of response types (a) for children and (b) for adults (hypotheses 1 and 2). The second part 
will focus on the comparison of the number of responses given by adults and children within the different types of responses. Thus, the proportion of syntagmatic, paradigmatic, clang and 'other' responses produced by adults will be compared with the proportion of responses produced by children in the respective categories (hypotheses 3, 4, and 5).

In order to test our hypotheses, we computed the percentage of each association category within each group and calculated one-way (goodness-of-fit) chi-squares in order to compare (a) the patterns of response type produced by each group (group-internal results), and (b) the frequency of responses within the different types of responses given by the two groups of participants.

Except for Nissen and Henriksen's study (2006), which showed that adult native speakers demonstrated a strong preference for syntagmatic over paradigmatic responses, results from most previous studies indicated that adult native speakers produce predominantly paradigmatic responses, especially when the prompt words are frequently occurring words (e.g., Entwisle 1966; Wolter 2001). On the basis of those studies, and taking into account that the present study employed the Kent-Rosanoff test, which consists of highly frequent prompt words, we expected that Greek adult speakers would produce a predominance of paradigmatic responses (hypothesis 1). However, the results of this study tend to agree with those of Nissen and Henriksen's (2006) study, as they indicate that adult participants produced a larger proportion of syntagmatic than paradigmatic responses. The difference between our study and that of Nissen and Henriksen's is that in the latter, Danish speakers indicated a strong preference for syntagmatic over paradigmatic responses $(54 \%$ vs. $32.8 \%$ ), whereas in the present study the difference is much smaller and the proportions of syntagmatic and paradigmatic responses tend to balance ( $47.2 \%$ vs. $46.1 \%$ ); no significant differences were found between the observed and expected frequencies for the two types of responses $\left(\chi^{2}=0.142, \mathrm{df}=1\right.$, $\mathrm{p}=0.706$ ) (Figure 1).

Based on the results of previous studies which showed that children up to 8 years old produce a predominance of syntagmatic and clang responses (see, e.g., Brown \& Berko 1960; Ervin 1961), we expected Greek young participants to give a higher proportion of syntagmatic than paradigmatic responses (hypothesis 2). However, Greek children of 7-8 years of age gave a predominance of paradigmatic responses $(50.4 \%)$, while only $19.9 \%$ of their associations were syntagmatic. A large proportion of their responses were unclassifiable $(20.2 \%)$, and only $8 \%$ were clang responses (Figure 2 ). The difference between the observed and expected frequencies for the two types of responses in children was found to be significant $\left(\chi^{2}=1284.92, \mathrm{df}=1, \mathrm{p}<.001\right)$. 


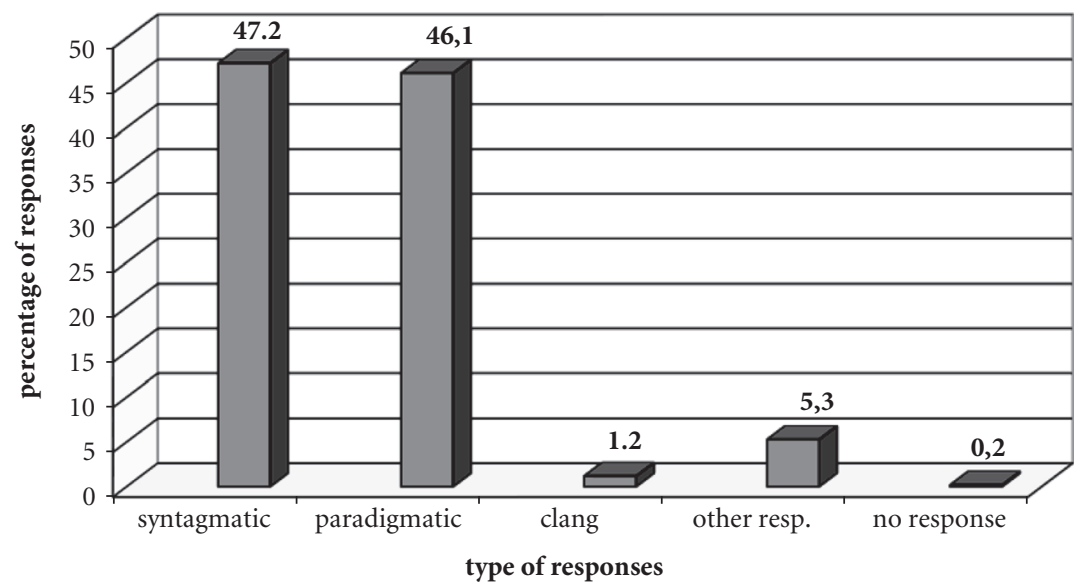

Figure 1. Mean proportion of response types produced by adults

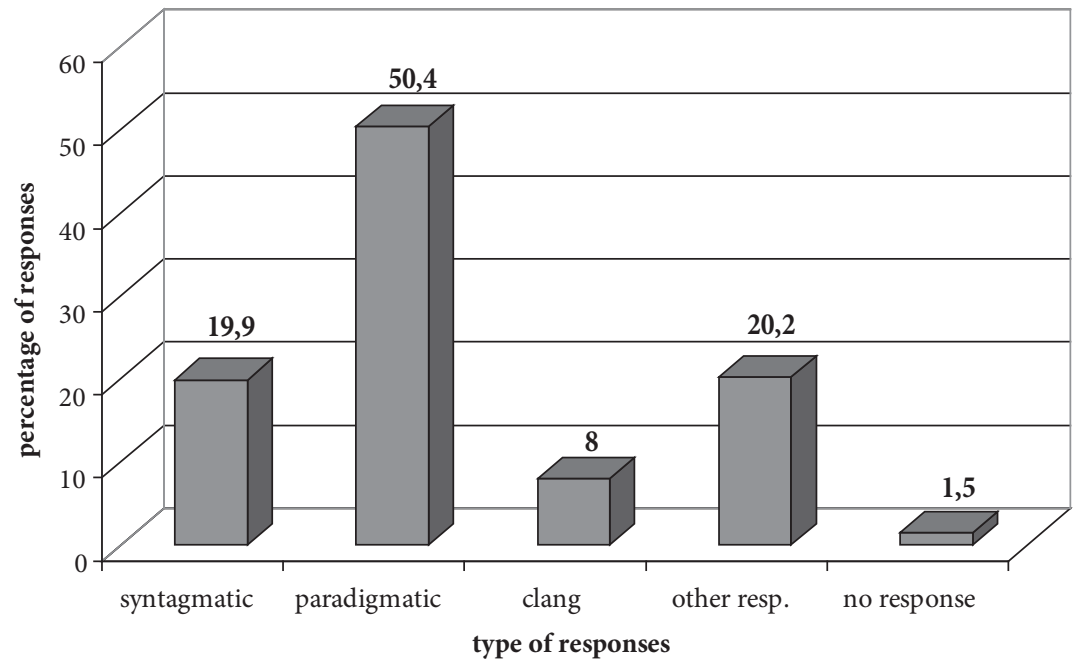

Figure 2. Mean proportion of response types produced by children

On the basis of the results of past research which indicated that adults and children produce predominantly paradigmatic and syntagmatic associations, respectively, hypothesis 3 predicted that the proportion of syntagmatic responses in children would be larger compared to the corresponding one 


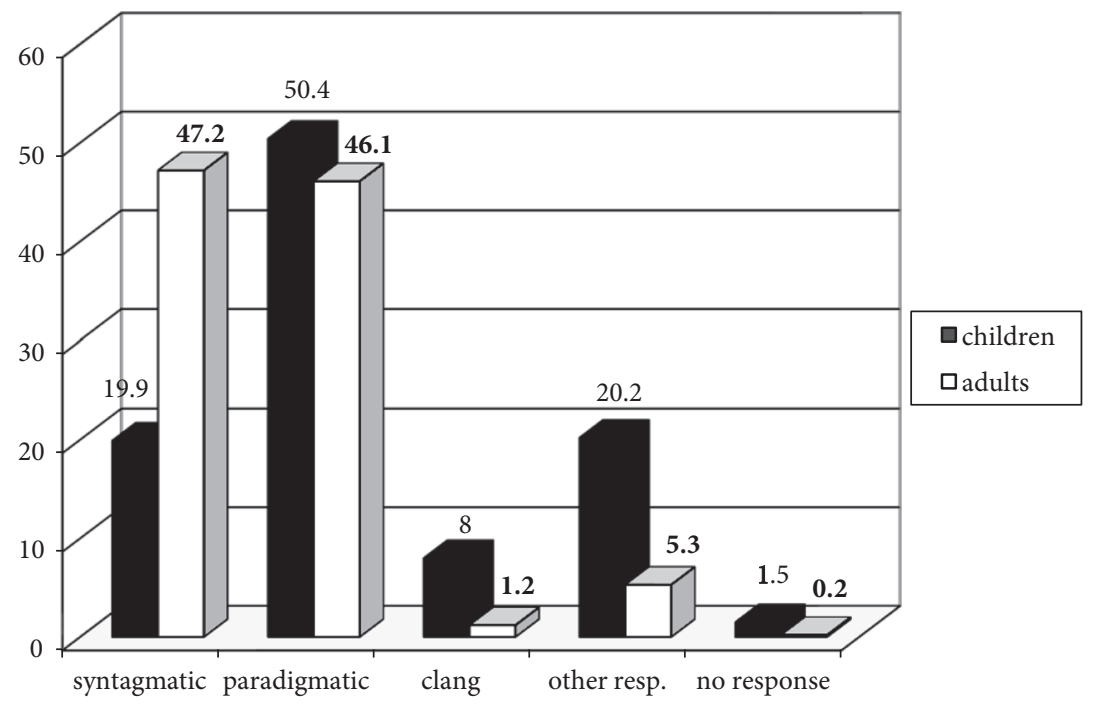

Figure 3. Mean proportion of response types produced by children and adults

in adults. Nevertheless, the results of the present study indicate that adults have produced more than double the proportion of syntagmatic associations produced by children (47.2\% vs. $19.9 \%$ ) (Figure 3 ). The difference between the observed and expected frequencies for children's and adults' syntagmatic responses was found to be statistically significant $\left(\chi^{2}=1013.76, \mathrm{df}=1\right.$, $\mathrm{p}<.001)$.

Following the same line of reasoning, hypothesis 4 predicted a larger proportion of paradigmatic responses produced by adults than by children. Contrary to our assumptions, the proportion of paradigmatic associations produced by children in the present study is higher than the corresponding one for adults (50.4\% vs. 46.1\%) (Figure 3). The difference between the observed and expected frequencies for children's and adults' paradigmatic responses was found to be statistically significant $\left(\chi^{2}=21.354, \mathrm{df}=1, \mathrm{p}<.001\right)$. This remains a surprising finding, as it does not agree with the results of any of the previous association studies.

Hypotheses 1, 2, 3, and 4 were not confirmed: Our results seem to suggest that Greek children tend to make mostly paradigmatic associations, whereas connections between frequent words in adults' mental lexicon are either syntagmatic or paradigmatic. At the same time, the comparison of the types of associations produced by the two groups of participants indicated that children produce a significantly higher proportion of paradigmatic responses than adults, while the proportion of syntagmatic associations produced by adults 
is significantly higher than the corresponding one for children. Thus, our findings do not seem to support the model of lexical development based on the syntagmatic-paradigmatic shift.

Results confirmed the final hypothesis according to which children were expected to produce more clang and nonsensical responses than adults. Thus, it was shown that there was a significant difference between the observed and expected frequencies for children's and adults' clang responses $(1.2 \%$ vs. $8 \%)$ $\left(\chi^{2}=484.50, \mathrm{df}=1, \mathrm{p}<.001\right)$. With respect to the 'unclassifiable' responses, the proportion produced by children was almost four times higher than the respective one for adults $\left(\chi^{2}=895.57, \mathrm{df}=1, \mathrm{p}<.001\right)$ (Figure 3 ).

As the effect of the frequency of stimulus words on patterns of responses has been an important issue in association studies (cf. Wolter 2001, among others), we conducted a correlation analysis between type of response and frequency of prompt words. What we found was a significant correlation between frequency and response type in children ( $\mathrm{rho}=0.21, \mathrm{df}=98, \mathrm{p}<.001)$, but not in adults. In particular, prompt words of higher frequency were found to elicit mostly paradigmatic responses by children.

In an attempt to further distinguish and classify adults' and children's responses, we looked into (a) the effect that the part of speech of the stimulus had on the responses elicited by the two groups of participants, and (b) whether there were specific items that prompted mainly paradigmatic or syntagmatic responses in each group. With respect to the first point, what we found was that in the adult group, nouns elicited mainly paradigmatic associations, whereas adjectives, verbs, and adverbs elicited mainly syntagmatic responses. By contrast, in children, only verbs elicited mainly syntagmatic associations whereas nouns, adjectives and adverbs triggered mostly paradigmatic responses. A correlation analysis performed between the part of speech of prompt words and the type of response elicited (i.e., paradigmatic vs. syntagmatic) indicated that there is a significant negative correlation between part of speech and type of response for both groups ( $r h o=-1.00, \mathrm{df}=3, \mathrm{p}<.001$ ). This means that participants' response patterns are negatively related to the part of speech of the prompt word.

As regards the second point, we tried to identify those prompt words that elicited more than $70 \%$ of paradigmatic or syntagmatic responses in each group. There were 26 such items in the adult group and 21 in the young participants group. In both groups, the majority of those items were nouns -16 out of 26 and 16 out of 21 - and, as expected perhaps, the majority of them elicited mostly paradigmatic responses in children and syntagmatic ones in adults. Finally, only six of them were common in both groups (deep, eating, fruit, spider, thirsty, doctor) and these elicited the same dominant type of response in both groups. 


\section{Discussion}

The syntagmatic-paradigmatic shift in responses to word association tests as this has been observed in native speakers' responses across several languages has led to the conclusion that the connections between frequent and wellknown words in the L1 mental lexicon are predominantly paradigmatic. Contrary to those findings, the results of the analyses performed in the present study suggest (a) that the connections between highly frequent words in Greek adults' mental lexicon are almost equally syntagmatic and paradigmatic, and (b) that Greek children (at the age of 7-8 years old) tend to make mostly semantic associations, with most connections between highly frequent words being paradigmatic. Such findings question the notion of the syntagmaticparadigmatic shift as an indication of lexical and cognitive development.

More particularly, our findings have indicated that Greek adult speakers' preference for syntagmatic associations is (a) only slightly stronger than their preference for paradigmatic responses ( $47.2 \%$ vs. $46.1 \%)$, (b) stronger than other native speakers' preference for syntagmatic responses in previous studies (cf. Postman \& Keppel 1970; Woodrow \& Lowell 1916; Wolter 2001), and, most importantly, (c) much stronger than Greek children's preference for syntagmatic associations (47.2\% vs. $19.9 \%)$. At the same time, children's responses showed an unexpected and surprisingly high predominance of paradigmatic over syntagmatic responses (50.4\% vs. 19.9\%). However, the present study is the first qualitative analysis of types of responses to the Greek version of the Kent-Rosanoff test, whereas there are well-documented response norms for the same test which cover different languages, ages and geographical locations (Postman \& Keppel 1970). It is necessary, therefore, to look for possible explanations in order to interpret the differences observed. In this attempt, we need to take into consideration factors such as morphological and syntactic characteristics of Greek as these may be partly responsible for the cross-linguistic diversity in word association patterns.

There are two issues in this study that need to be accounted for: (a) adults' relative preference for syntagmatic responses, and (b) Greek children's strong preference for paradigmatic responses.

When one examines the body of research so far conducted, it becomes clear that most researchers have placed emphasis on the differences observed between groups in the proportion of paradigmatic responses, without examining the corresponding differences in the proportion of syntagmatic responses (cf. Wolter 2001). Wolter (2001), in particular, challenged the long-lived theory about the syntagmatic-paradigmatic shift and assigned the findings of older studies to their design (see also Söderman 1993). The results of his 
research actually suggested that (a) as we grow up what is actually happening is a shift from semantically meaningless (i.e., clang and unclassifiable) responses to semantically meaningful ones. In other words, there is a decrease of clang and 'other' responses but an increase in the proportion of paradigmatic and syntagmatic responses; (b) the proportion of syntagmatic responses produced by native speaker informants increases when the prompt words are relatively infrequent words. Based on the results of his research with both L1 and L2 advanced speakers, Wolter concluded that paradigmatic responses do not represent a higher level of lexical development as it takes a great deal of lexical knowledge to be able to relate a response sequentially (i.e. syntagmatically) to the prompt word; thus he questioned previous claims about the L1 mental lexicon being paradigmatically dominated.

Söderman's study (1993), which also examined native and proficient nonnative speakers, found that neither group showed a very strong paradigmatic dominance for the frequent prompt words. On the basis of her findings, the researcher concluded that "there may not be such a marked shift from syntagmatic to paradigmatic responses after all," but rather a fairly stable balance between the two categories (p. 156). Therefore, she argued, a paradigmatic response may not necessarily represent the highest level of lexical knowledge.

A comparison between word association responses in English and Italian, among other languages, indicated that Italian adult speakers gave a large number of syntagmatic responses. This finding is particularly important as Italian is a highly inflected language similar to Greek (Rosenzweig 1961).

More recently, Nissen and Henriksen (2006) questioned the validity of the notion that a syntagmatic-paradigmatic shift is indicative of lexical and cognitive development, as their Danish native informants produced a predominance of syntagmatic responses to high-frequency prompt words. The particular study did not employ the Kent-Rosanoff list but words from Nation's Vocabulary Levels Test and thus there are no available response norms with which to compare Danish speakers' responses.

One reason for the discrepancy observed between the findings of this study and those of previous ones might be the different criteria adopted for the classification of responses. Most of the research in support of the syntagmaticparadigmatic shift has been conducted in English. However, very few of the researchers involved in those studies have commented on the difficulty of distinguishing between paradigmatic and syntagmatic associations in English. More particularly, the fact that in English a given word may actually belong to several grammatical classes creates problems in the classification of the associations produced. Deese (1965) stressed the significance of this problem for the characterization of associative structure, and Meara (1982) suggested that the 
distinction is important since it underlies the phenomenon of the shift in response type. In addition, the sequence of two nouns in English, as in Greek, creates a noun phrase (e.g., toy-factory). In a case like this, even though stimulus and response belong to the same grammatical class, they demonstrate a sequential relation and their association may be regarded as syntagmatic (cf. Wolter 2001). Similar instances are not rare, yet researchers do not usually comment on either the problem they present or on the method adopted for their classification. However, alternative classifications might produce different proportions of syntagmatic and paradigmatic associations.

Explanations for the different response patterns given by Greek and English native speakers could be sought in differences between the Greek and English syntax, and, consequently, in the classification of Greek speakers' responses. Nissen and Henrikssen (2006) have suggested that word order and gender effects in different languages might influence association responses differently. As already stated, in our study, a noun response to a noun stimulus was classified as a syntagmatic association if the response produced was in the genitive case. In Greek, the sequence "noun in the nominative case" + "noun in the genitive case" is clearly a noun phrase (e.g., vasilias - liontarion, literally meaning 'king of the lions'). As the majority of prompt words in the Kent-Rosanoff list are nouns, a large number of the responses demonstrated such a sequential relation and were therefore classified as syntagmatic. Also, in Greek, as already stated, adjectives precede nouns. Furthermore, both nouns and adjectives follow the same declensional patterns and adjectives have all three genders in agreement with the noun. These morpho-syntactic features might have prompted the large number of syntagmatic responses (i.e., nouns) to adjectives as compared to nouns, at least in the adult group (e.g., skotinosthalamos ('dark'-'room'), makris-dhromos ('long'-'road'), mavro-foustani ('black'-dress'), argos-thanatos, ('slow'-death'), etc.). However, it is worth noting, that quite often the responses provided violated the rules stated above. In particular, adjectives sometimes elicited nouns of different gender (e.g., lios (masc.) - epifania (fem.) ('smooth'-'surface'), omorfos (masc.) - kopela (fem.) ('beautiful'-'girl'), psilos (masc.) - kiparisi (neuter) ('high'-'cypress'), aspros (masc.) - chioni (neuter) ('white'-'snow'), etc.). Additionally, although adjectives typically precede nouns in Greek and the opposite order is possible as a marked alternative, there were many cases of nouns eliciting adjectives, e.g. provato-aspro ('sheep'-'white'), spiti-oreo ('house'-'pretty'), fruto-sapjo ('fruit'-'rotten'), etc.

Adults' relative preference for syntagmatic responses in our study brings forward Entwisle's notion of late syntagmatic responses (1966), which Namei also included in her model of development of word-knowledge (2004). 
Although associative studies suggest that the L1 adult mental lexicon is predominantly paradigmatically organized, Entwisle (1966) found that adult native speakers tended to provide a predominance of syntagmatic associations that were different from children's syntagmatic associations. More particularly, they were described as "enlargements in meaning, a more flexible and richer interpretation of a concept ..." (Entwisle 1966: 74). Late syntagmatic responses include low-frequency words and abstract combinations and are considered to be an indication of a more abstract mode of organization of the mental lexicon (see e.g., Entwisle 1966; Namei 2004). According to Namei (2004), paradigmatic and late syntagmatic responses represent the same degree of word knowledge; thus well-known words elicit either paradigmatic or late syntagmatic associations. Taking into account that nearly all prompt words of the Kent-Rosanoff list are highly frequent words, we must assume that they are all well known and well integrated in the mental lexicon of the adult participants. Although syntagmatic responses in our study were not classified as early or late syntagmatic, the fact that some of the prompt words elicited paradigmatic associations while others syntagmatic ones, might lead us to assume that at least some of the latter belong to the late syntagmatic responses, and this might partly account for the balanced structure of the Greek adult mental lexicon. Late syntagmatic associations in our data include idiomatic and figurative expressions that resulted from the association of certain stimulus words with the responses provided (e.g., kefali-ajiristo ('head'-'unturnable', that is, 'a stubborn person'), mnimi-elefanta ('memory-of an elephant', that is, 'very good memory'), associations that make reference to well-known Greek proverbs (e.g., pinasmenos-karvelia ('hungry'-'loaves of bread') or associations that indicate a richer understanding of the stimulus provided (e.g., tetragonoikodhomiko ('square'-'constructive', i.e. 'block of flats').

With reference to Greek children's preference for paradigmatic responses, Ervin (1961) and Entwisle et al. (1964) found that children between 6 and 8 years old demonstrate a definite shift from syntagmatic to paradigmatic responses; that is, as children grow up, they tend to produce a higher proportion of paradigmatic responses. However, none of those early investigations into the lexical development of native-speaking children found such a strong preference for paradigmatic responses. At the same time, comparisons between Greek and English native-speaking children's proportion of response types are difficult to make as researchers' attention was focused only on the increasing tendency of paradigmatic responses whereas corresponding differences in the proportion of syntagmatic responses were only assumed (see also Wolter 2001). Therefore, how can we account for Greek native-speaking children's strong preference for paradigmatic associations? According to Cronin (2002), 
the part of speech of the stimulus words seems to influence paradigmatic responding. Entwisle (1966) found that young children of four and five years of age responded with a noun to any prompt word. Similarly, Brown and Berko (1960) found a high proportion of noun responses to noun stimulus words. Also, according to Nelson (1977), the responses to noun prompt words tend to be paradigmatic from a young age, and the syntagmatic-paradigmatic shift is seen most often with adjectives. Recall at this point that in our study Greek children gave a predominance of paradigmatic responses not only to nouns but also to adjectives and adverbs. The fact that only verbs elicited mostly syntagmatic responses in children, as opposed to nouns, adjectives, and adverbs may be related to Borer's claim (2004, cited in Tsimpli 2006) that verb forms in children are not retrieved from the lexicon but are computed 'on-line' on the basis of syntactic rules. This might explain children's tendency to associate verbs with nouns, pronouns and adverbs and thus produce syntagmatic associations. This claim received support from Tsimpli (2006) who, on the basis of her research on children's interpretation of voice morphology in Greek, argued that grammar (essentially what one would understand as morphosyntax) takes priority over lexical and pragmatic constraints in children.

The Kent-Rosanoff list consists mostly of noun words, the overwhelming majority of which are concrete nouns. It is possible that, besides frequency, the feature [ \pm concrete] may affect the type of response evoked by nouns. Psycholinguistic studies have demonstrated that abstract words are more difficult to process than concrete words in various cognitive tasks, and this observation is referred to as the "concreteness effect" (Rubin 1980; Bleasdale 1987; DeGroot 1989; see also Manouilidou \& Kehayia 2004). Two theoretical models have been proposed to account for the concreteness effect; the dual-coding theory (Paivio 1986, 1991) and the context availability theory (Schwanenflugel \& Shoben 1983). The former postulates that the processing of abstract nouns relies on symbolic codes in the left hemisphere, whereas concrete nouns additionally activate image-based representations in the right hemisphere. The alternative account postulates that concrete nouns are processed faster because they have a larger contextual support than abstract nouns. More recent studies have actually argued against a single exclusive theory of the concreteness effect and have supported a combination of both models (Jessen et al. 2000; Fiebach \& Friederici 2003). Furthermore, in line with the suggestion of dual-coding theory that there is increased activation in a system of imaginal representations for concrete words, Fiebach and Friederici's (2003) study demonstrated that during the processing of concrete words there is also increased neural activity in the left basal temporal cortex; this area is associated with higher-level visual processing and mental imagery. It is possible that the 
activation of images during the processing of concrete words may actually facilitate their association with other concrete nouns and therefore the formation of paradigmatic associations. Although a correlation analysis would be appropriate in order to support the concreteness effect on response patterns, the list does not contain enough items of both [+concrete] and [-concrete] nouns to allow such analysis to be performed.

A factor that seems to influence children's preference for paradigmatic responses is the frequency of the prompt words used. Although Wolter (2001) questioned the effect of word frequency, as an objective measurement, on the structure of the mental lexicon, the results of our analysis actually indicated that frequency does have an effect on the response patterns produced by children and that most of the words of the list, which are highly frequent, tend to elicit paradigmatic responses by this group of participants. That being said, we should also point out that some of the less frequent items on the list also elicited paradigmatic responses (e.g., velona ('needle'), tetragono ('square'), psali$d h i$ ('scissors'), etc.). This might be attributed to children's familiarity with these words, either within their school or family context. Recall here that these words were found in their textbooks, and thus children had been exposed, implicitly or explicitly, to them at school. This finding provides support to Wolter's (2001) argument regarding the importance of depth of word knowledge, that is, the degree to which the speaker knows a word, as compared to objective measurements of frequency.

The role of the educational context and its effect on children's responses is an issue that has been scarcely discussed in relevant studies. A comparison between school textbooks, materials, and methods employed in different L1 educational contexts might also provide relevant information about how children are taught and expected to learn words in their mother tongue. In Greece, for example, textbooks seem to place emphasis on thematic clustering and presentation of words, thus facilitating paradigmatic organization. However, these are just observations, and as such they do not allow us to draw any conclusions. It is suggested, though, that future research take such variables into consideration.

Frequency of the prompt words does not seem to have the same effect on the associations elicited by adults as no significant correlation was found between frequency of items and patterns of response (paradigmatic vs. syntagmatic) in this group. Thus, word frequency, as this is estimated on the basis of corpus findings, may not have the same effect on the associations elicited by children and adults.

Finally, with respect to children's 'unclassifiable' responses, the proportion produced by them was almost four times higher than the respective one for adults; this finding confirmed our initial hypothesis, and is corroborated by 
findings of other similar studies (cf. Ervin 1961, Wolter 2001, Namei 2004). Perceptual similarity is obviously important in children's mental lexicon; as they grow older, meaning-based associations gradually replace formal similarity and connections between words become increasingly semantic. Children's unclassifiable responses included either non-existent words or words that were not in any obvious way semantically related to the prompts, e.g., luludhi-feroto? ('flower'-non-existent word), mnimi-dhimokratia ('memory'-'democracy'), dhikeosini-trapezi ('justice'-'table'), etc.

On the basis of our findings, then, it is only reasonable to assume that connections between highly frequent and well-known nouns in the mental lexicon of the Greek child are predominantly paradigmatic. It is clear that the results of our study do not support the cross-linguistic generalizability of word association patterns as they question the notion of the syntagmatic-paradigmatic shift, as well as previous claims regarding the paradigmatic associations as a sign of well- or better-known words (cf. Söderman 1993; Nissen \& Henriksen 2006). Greek speakers seem to behave differently from other native speakers, given that our findings suggest that there is actually a shift from paradigmatic to both syntagmatic and paradigmatic responses, a finding which runs contrary to the results of prior research. At the same time we could suggest that the shift is from a less semantically to a more semantically organized lexicon, where the emphasis should be placed on the increasing proportion of semantic associations and the correspondingly decreasing proportion of clang and 'other' responses (rather than on the differences in the proportions of syntagmatic and paradigmatic responses produced). The organization of the Greek mental lexicon seems to be equally syntagmatic and paradigmatic since adult native speakers' responses balance between the two types of associations. Thus, word association patterns cannot be generalized across languages. Our data do not corroborate results of previous similar studies in other languages, and it would be interesting in this respect to compare the Greek response norms with those of languages with rich morphology, like Italian or Spanish, for example.

In order to interpret our findings, we examined the effect of frequency and grammatical class of prompt words on the associations produced by the two groups of participants. Only frequency was found to have a clear effect on the associations produced by children. Claims about the effect of Greek morpho-syntax on the associations elicited, and therefore on the structure of the mental lexicon, are difficult to support, inasmuch as the selection of prompt words in the Kent-Rosanoff list does not include a variety of different morphosyntactic properties. Future research should take this into account and make appropriate adjustments and/or additions to the elicitation instrument used. 


\section{Conclusion}

The present study set out to examine the associative patterns produced by Greek speaking children and adults to a hundred highly frequent words in Greek. Our aim was to test the concept of the syntagmatic-paradigmatic shift by exploring whether it applied in the case of the Greek mental lexicon. We chose to use a translated version of the original Kent-Rosanoff test as this would allow us to draw comparisons between the patterns of responses produced by Greek speakers and speakers of other languages to the same prompt words. The results of such comparison were expected to provide answers regarding the generalizability of word association patterns across languages.

Our findings did not provide support for the shift in response type, given that the associative patterns produced by both young and adult participants in this study are at odds with previous studies. Thus, our results question the generalizability of the association patterns obtained in other languages. In an attempt to account for the discrepancies observed between our study and previous ones, we looked into the effects of frequency and of the part of speech of the stimulus words on the formation of association patterns. We also suggested that morpho-syntactic features may be partly responsible for Greek speakers' responses to the prompts given; such features have been shown to be responsible, at least partly, for the cross-linguistic variability in word association patterns (see also Gósy \& Kovács 2002). However, further research is required in this direction with the use of a different list of prompt words which will allow us to control particular morphosyntactic properties.

The predominance of paradigmatic associations in Greek children's responses together with adults' relative preference for syntagmatic responses points to the need for re-examining the concept of the syntagmatic-paradigmatic shift as an indication of lexical and cognitive development. A point that is clearly supported by our findings is that young children's mental lexicon is semantically organized, but it also contains several clang and 'other' associations; the adult mental lexicon is mainly semantically organized - equally syntagmatically and paradigmatically. On the basis of our findings and taking into account the results of recent studies into the organization of the L1 and L2 mental lexicons (cf. Nissen \& Henriksen 2006), we would like to suggest that perhaps we should not be talking about a syntagmatic-paradigmatic shift: this concept has not always been corroborated by data in word association studies, and therefore claims regarding the paradigmatic organization of the L1 mental lexicon have been questioned. However, associative studies unambiguously point to a common finding, which can be characterized as a shift from clang and 'other' responses to semantically meaningful ones, either syntagmatic or paradigmatic. This entails that there may be words in the mental 
lexicon which will never form paradigmatic associations; however, such a relation is not indicative of a lower degree of lexical knowledge (cf. Wolter 2001). As Nissen and Henriksen (2006) have suggested, prompt words in a word association test tend to activate various nuances and aspects of word meaning, and participants' responses to them are much more than a linguistic reaction. They express personal experiences, points of view, and visualizations, and these may result in either syntagmatic or paradigmatic associations with the prompt words given. The notion of a shift from meaningless to meaningful responses seems to capture the rich variety of relations between words as well as the various ways in which they are known and used by the speakers of a language. This shift does not suggest that phonologically or nonsemantic connections are just replaced and lost; rather, according to Wolter's Developmental Model (2001), older connections are retained but the semantic ones become dominant. This suggestion is also in line with Namei's (2004) word-knowledge continuum. According to her, the mental lexicon contains words which are at different stages of development moving on a wordknowledge continuum from partial to precise knowledge: words that are barely known will elicit mostly clang associations, whereas well known words will tend to have all types of connections, but the semantic ones will be stronger. This shift from meaningless to meaningful responses should be seen as a developmental feature of every individual word and an indication of increased lexical knowledge and cognitive development.

\section{References}

Aitchison, Jean. 1987. Words in the Mind. Oxford: Blackwell Publishing.

Bleasdale, Fraser A. 1987. Concreteness-dependent associative priming: Separate lexical organization for concrete and abstract words. Journal of Experimental Psychology: Learning, Memory and Cognition 13: 582-594.

Brown, Roger \& Jean Berko. 1960. Word associations and the acquisition of grammar. Child Development 31: 1-14.

Carreiras, Manuel, Eva Gutiérrez-Sigut, Silvia Baquero \& David Corina. 2008. Lexical processing in Spanish Sign Language (LSE). Journal of Memory and Language 58(1): $100-122$.

Cramer, Phebe. 1968. Word Association. New York: Academic Press.

Cronin, Virginia S. 2002. The syntagmatic-paradigmatic shift and reading development. Journal of Child Language 29: 189-204.

Deese, James. 1965. The Structure of Associations in Language and Thought. Baltimore: Johns Hopkins Press.

DeGroot, Annette M.B. 1989. Representational aspects of word imageability and word frequency as assessed through word association. Journal of Experimental Psychology: Learning, Memory and Cognition 15: 824-845. 
Entwisle, Doris R. 1966. Word Associations of Young Children. Baltimore: Johns Hopkins University Press.

Entwisle, Doris R., Daniel F. Forsyth \& Rolf Muuss. 1964. The syntactic-paradigmatic shift in children's word associations. Journal of Verbal Learning and Verbal Behavior 3: 19-29.

Ervin, Susan M. 1961. Changes with age in the verbal determinants of word association. American Journal of Psychology 74: 361-372.

Fay, David A. \& Anne Cutler. 1977. Malaproprisms and the structure of the mental lexicon. Linguistic Inquiry 8: 505-520.

Fiebach, Christian J. \& Angela D. Friederici. 2003. Processing concrete words: fMRI evidence against a specific right-hemisphere involvement. Neuropsychologia 42: 62-70.

Fitzpatrick, Tess. 2006. Habits and rabbits: Word associations and the L2 lexicon. In EUROSLA Yearbook 6: 121-145.

Forster, Kenneth. I. F. \& Susan Chambers. 1973. Lexical access and naming time. Journal of Verbal Learning and Verbal Behavior 12: 627-635.

Goldinger, Stephen D., Thomas J. Palmeri \& David B. Pisoni. 1992. Words and voices: perceptual details are preserved in lexical representations. ICSLP: 591-594.

Gósy, Maria \& Magdolna Kovács. 2002. The mental lexicon: Results of some word association experiments. Acta Linguistica Hungarica 49(2): 179-224.

Hirsh, Katherine W. \& Jeremy J. Tree. 2001. Word association norms for two cohorts of British adults. Journal of Neurolinguistics 14(1): 1-44.

Holton, David, Peter Mackridge \& Irene Philippaki-Warburton. 1999. Greek: A Comprehensive Grammar of the Modern Language. London: Routledge.

Jarema, Gonia, Gary Libben, Wolfgang U. Dressler \& Eva Kehayia. 2002. The role of typological variation in the processing of interfixed compounds: Evidence from German, Polish and Greek. Brain and Language 81: 736-747.

Jessen, Frank, Reinhard Heun, Michael Erb, Dirk-Oliver Granath, Uwe Klose, Andreas Papassotiropoulos \& Wolfgang Grodd. 2000. The concreteness effect: Evidence for dual coding and context availability. Brain and Language 74: 103-112.

Joannopoulou, Marina (2007). Word association tests in English and Greek: The syntagmaticparadigmatic shift revisited. In Anieza Kavadia, Marina Joannopoulou \& Anastasios Tsangalidis (eds.), Proceedings of the $13^{\text {th }}$ International Conference in Applied Linguistics, 518-531. Thessaloniki: Greek Applied Linguistics Association.

Joseph, Brian D. \& Philippaki-Warburton Irene. [1987] 1989. Modern Greek. New York: Routledge.

Kehayia, Eva. 1997. Lexical access and representation in individuals with developmental language impairment: A cross-linguistic study. Journal of Neurolinguistics 10(2-3): 139-149.

Kehayia, Eva, Gonia Jarema, Kyrana Tsapkini, Danuta Perlak, Angela Ralli \& Danuta Kadzielawa. 1999. The role of morphological structure in the processing of compounds: The interface between linguistics and psycholinguistics. Brain and Language 68: 370-377.

Kent, Grace H. \& Aaron J. Rosanoff. 1910. A study of association in insanity. American Journal of Insanity 67: 37-39.

Libben, Gary \& Gonia Jarema. 2002. Mental lexicon research in the new millennium. Brain and Language 81: 2-11.

Maniou-Vakali, Maria, Efthymia Sygollitou \& Anastasia Kostaridou-Efkleidi 1984. Normes Syneirmon 783 Ousiastikon tou Ellinikou Lexilogiou ['Associatiative norms of 783 nouns of the Greek vocabulary']. Epistimoniki Epetirida Philosphikis Skholis, Thessaloniki: Aristotle University of Thessaloniki.

Manouilidou, Christina \& Eva Kehayia. 2004. Lexical access and representation of Modern Greek derived words with the suffix - dzis. Journal of Greek Linguistics 5: 81-96. 
Marslen-Wilson, William D. 1987. Functional parallelism in spoken word recognition. Cognition 25: 71-102.

Marslen-Wilson, William D., Helen E. Moss \& Stef van Halen. 1996. Perceptual distance and competition in lexical access. Journal of Experimental Psychology: Human Perception and Performance 22(6): 1376-1392.

McNeill, David. 1970. The Acquisition of Language: The Study of Developmental Psycholinguistics. New York: Harper \& Row Publishers.

Meara, Paul. 1982. Word associations in a foreign language: A report on the Birkbeck Vocabulary Project. Nottingham Linguistic Circular 11: 29-37.

Meara, Paul. 2009. Connected Words: Word Associations and Second Language Vocabulary Acquisition. Amsterdam/Philadelphia: John Benjamins.

Namei, Shidrokh. 2004. Bilingual lexical development: a Persian-Swedish word association study. International Journal of Applied Linguistics 14(3): 363-388.

Nelson, Katherine. 1977. The syntagmatic-paradigmatic shift revisited: a review of research and theory. Psychological Bulletin 84: 93-116.

Nissen, Henriette B. \& Birgit Henriksen. 2006. Word class influence on word association test results. International Journal of Applied Linguistics 16(3): 389-408.

Paivio, Allan. 1986. Mental Representations: A Dual-Coding Approach. Oxford: Oxford University Press.

Paivio, Allan. 1991. Dual-coding theory: Retrospect and current status. Canadian Journal of Psychology 45(3): 255-287.

Palermo, David S. 1971. Characteristics of word association responses obtained from children in grades one through four. Developmental Psychology 5: 118-123.

Palermo, David S. \& James Jenkins. 1964. Word Association Norms. Minneapolis: University of Minnesota Press.

Plag, Ingo. 2003. Word-formation in English. Cambridge: Cambridge University Press.

Postman, Leo. 1970. The California norms: Association as a function of word frequency. In Leo Postman \& Geoffrey Keppel (eds.), Norms of Word Association, 241-320. New York: Academic Press.

Postman, Leo \& Geoffrey Keppel (eds.) 1970. Norms of Word Association. New York: Academic Press.

Rosenzweig, Mark R. 1961. Comparisons among word-association responses in English, French, German and Italian. American Journal of Psychology 74: 347-360.

Rosenzweig, Mark R. 1970. International Kent-Rosanoff word association norms, emphasizing those of French male and female students and French workmen. In Leo Postman \& Geoffrey Keppel (eds.), Norms of Word Association, 95-176. New York: Academic Press.

Rubin, David C. 1980. 51 Properties of 125 words: A unit analysis of verbal behavior. Journal of Verbal Learning and Verbal Behavior 19(6): 736-755.

Schmitt, Norbert. 2000. Vocabulary in Language Teaching. Cambridge: Cambridge University Press.

Schwanenflugel, Paula J. \& Edward Shoben. 1983. Differential context effects in the comprehension of abstract and concrete verbal materials. Journal of Experimental Psychology: Learning, Memory and Cognition 9: 82-102.

Söderman, Tove. 1993. Word associations of foreign language learners and native speakers: The phenomenon of a shift in response type and its relevance for lexical development. In Hakan Ringbom (ed.), Near-native Proficiency in English, 91-182. Abo: Abo Akademi Foundation.

Stolz, Walter S. \& Janice Tiffany. 1972. The production of "child like" word associations by adults to unfamiliar adjectives. Journal of Verbal Learning and Verbal Behavior 11: 38-46.

Szalay, Lorand B., Charles Windle \& Dale A. Lysne. 1970. Attitude measurement by free verbal associations. The Journal of Social Psychology 82: 43-55. 
Tsapkini, Kyrana, Gonia Jarema \& Eva Kehayia. 2002. Regularity revisited: Evidence from lexical access of verbs and nouns in Greek. Brain and Language 81: 103-119.

Tsapkini, Kyrana, Gonia Jarema \& Eva Kehayia. 2004. Regularity re-revisited: Modality matters. Brain and Language 89: 611-616.

Tsimpli, Ianthi Maria. 2006. The acquisition of voice and transitivity alternations in Greek as native and second language. In Sharon Unsworth, Teresa Parodi, Antonella Sorace \& Martha Young-Scholten (eds.), Paths of Development in L1 and L2 Acquisition, 15-55. Amsterdam/Philadelphia: John Benjamins.

Wolter, Brent. 2001. Comparing the L1 and L2 mental lexicon. Studies in Second Language Acquisition 23: 41-69.

Woodrow, Herbert \& Frances Lowell. 1916. Children's association frequency tables. Psychology Monographs 22(5). No. 97. 


\section{Appendix I}

The Greek version of the Kent-Rosanoff test.

Instructions (adults' version):

- The following list includes 100 words. Next to each one write down the first word that comes to your mind.

- There are no correct or wrong responses; do not go back to erase or change your responses.

- Please provide only one response to each stimulus word.

- Avoid skipping words.

Instructions (children's version):

- What you have in your hands is a list of words.

- Read each word and next to it write the first word that comes to your mind.

- Try not to skip any word.

- There are no correct or wrong responses; do not go back to erase or change your responses.

\begin{tabular}{|c|c|c|c|}
\hline$\tau \rho \alpha \pi \varepsilon^{\prime} \zeta_{1}$ & neuter noun & $\lambda \circ \lambda_{0}$ ov́ $\delta \mathrm{r}$ & neuter noun \\
\hline 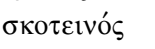 & adjective & $\lambda \alpha^{\prime} \mu \pi \alpha$ & feminine noun \\
\hline ноvбıки́ & feminine noun & óveipo & neuter noun \\
\hline$\alpha \rho \rho \omega ́ \sigma \tau \imath \alpha$ & feminine noun & 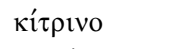 & adjective \\
\hline$\alpha ́ \alpha \delta \rho \alpha \varsigma$ & masculine noun & $\psi \omega \mu i^{\prime}$ & neuter noun \\
\hline$\beta \alpha \theta v_{s}$ & adjective & 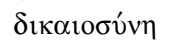 & feminine noun \\
\hline$\mu \alpha \lambda \alpha \kappa o ́ \varsigma$ & adjective & $\alpha \gamma o ́ p \imath$ & neuter noun \\
\hline$\tau \rho \omega \omega \omega$ & verb & $\varphi \omega \varsigma$ & neuter noun \\
\hline ßovvó & neuter noun & 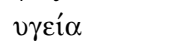 & feminine noun \\
\hline$\sigma \pi i ́ \tau \imath$ & neuter noun & Bíß入os & feminine noun \\
\hline 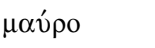 & adjective & $\mu v \eta ́ \mu \eta$ & feminine noun \\
\hline$\alpha \rho v i ́$ & neuter noun & $\pi \rho o ́ \beta \alpha \tau o$ & neuter noun \\
\hline 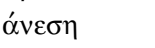 & feminine noun & $\mu \pi \alpha ́ v 10$ & neuter noun \\
\hline$\chi \chi^{\prime} \rho 1$ & neuter noun & $\alpha \gamma \rho \circ \tau o ́ \sigma \pi \imath \tau o$ & neuter noun \\
\hline коvтós & adjective & 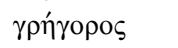 & adjective \\
\hline 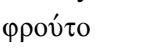 & neuter noun & $\mu \pi \lambda \varepsilon$ & adjective \\
\hline$\pi \varepsilon \tau \alpha \lambda \circ \sigma^{\prime} \delta \alpha$ & feminine noun & 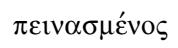 & deverbal adjective \\
\hline$\lambda$ cíos & adjective & $\pi \alpha \pi \alpha \varsigma_{\varsigma}$ & masculine noun \\
\hline$\delta 1 \alpha \tau \alpha \gamma \dot{\eta}$ & feminine noun & $\omega \kappa \varepsilon \alpha v o ́ \varsigma$ & masculine noun \\
\hline 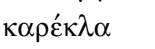 & feminine noun & $\kappa \varepsilon \varphi \alpha^{\prime} \lambda_{\mathrm{l}}$ & neuter noun \\
\hline
\end{tabular}

(Continued) 


\begin{tabular}{|c|c|c|c|}
\hline$\gamma \lambda v \kappa o ́ \varsigma$ & adjective & poúpvos & masculine noun \\
\hline$\sigma \varphi v \rho i ́ \chi \tau \rho \alpha$ & feminine noun & 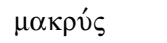 & adjective \\
\hline 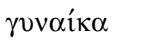 & feminine noun & $\theta \rho \eta \sigma \kappa \varepsilon i ́ \alpha$ & feminine noun \\
\hline крv́o & neuter noun & ovíoкv & neuter noun \\
\hline$\alpha \rho \gamma o ́ \varsigma$ & adjective & $\pi \alpha 1 \delta i ́$ & neuter noun \\
\hline 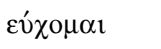 & verb & $\pi$ «крó $\varsigma$ & adjective \\
\hline$\pi \mathrm{o} \tau \alpha \mu \mathrm{o} \varsigma$ & masculine noun & $\sigma \varphi v \rho i ́$ & neuter noun \\
\hline$\alpha ́ \alpha \pi \rho \circ \varsigma$ & adjective & 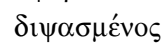 & deverbal adjective \\
\hline о́норфо & adjective & $\pi \hat{\lambda} \lambda \eta$ & feminine noun \\
\hline 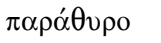 & neuter noun & $\tau \varepsilon \tau \rho \alpha ́ \gamma \omega \nu o$ & neuter noun \\
\hline$\tau \rho \alpha \chi v ́ s$ & adjective & 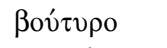 & neuter noun \\
\hline 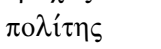 & masculine noun & $\gamma l \alpha \tau \rho o ́ \varsigma$ & masculine noun \\
\hline$\pi$ ó $\delta \mathrm{t}$ & neuter noun & $\delta v v \alpha \tau \alpha ́$ & adverb \\
\hline$\alpha \rho \alpha ́ \chi \vee \eta$ & feminine noun & $\kappa \lambda \varepsilon^{\prime} \varphi \tau \eta \varsigma$ & masculine noun \\
\hline$\beta \varepsilon \lambda \operatorname{có} \alpha$ & feminine noun & 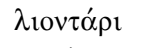 & neuter noun \\
\hline ко́ккиvо & adjective & $\chi \alpha \rho \alpha ́$ & feminine noun \\
\hline v́ $\pi v \circ \varsigma$ & masculine noun & $\kappa \rho \varepsilon \beta \alpha ́ \tau_{1}$ & neuter noun \\
\hline$\theta v \mu o ́ s$ & masculine noun & 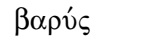 & adjective \\
\hline$\chi \alpha \lambda i^{\prime}$ & neuter noun & 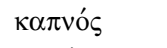 & masculine noun \\
\hline корі́ $\tau \iota$ & neuter noun & $\mu \omega \rho \operatorname{s}^{\prime}$ & neuter noun \\
\hline$\psi \eta \lambda{ }^{\prime} \varsigma$ & adjective & $\varphi \varepsilon \gamma \gamma \alpha \dot{\rho} \rho$ & neuter noun \\
\hline$\varepsilon \rho \gamma \alpha \sigma i ́ \alpha$ & feminine noun & $\psi \alpha \lambda i \delta$ & neuter noun \\
\hline Gıvós & adjective & 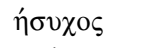 & adjective \\
\hline$\gamma \eta$ & feminine noun & $\pi \rho \alpha ́ \sigma ı v o$ & adjective \\
\hline$\varphi \alpha \sigma \alpha \rho i ́ \alpha$ & feminine noun & $\alpha \lambda \alpha^{\prime} \tau \imath$ & neuter noun \\
\hline$\sigma \tau \rho \alpha \tau \imath \dot{\omega} \tau \eta \varsigma$ & masculine noun & $\delta \rho o ́ \mu о \varsigma$ & masculine noun \\
\hline$\lambda \alpha \alpha_{\chi} \alpha v_{0}$ & neuter noun & $\beta \alpha \sigma \imath \lambda ı \alpha_{\varsigma}$ & masculine noun \\
\hline$\sigma \kappa \lambda \eta \rho o ́ \varsigma$ & adjective & tupí & neuter noun \\
\hline$\alpha \eta \tau o ́ s$ & masculine noun & $\mu \hat{i} \sigma \chi \circ \varsigma$ & masculine noun \\
\hline$\sigma \tau о \mu \alpha \alpha^{\prime} \chi 1$ & neuter noun & 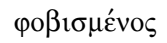 & deverbal adjective \\
\hline
\end{tabular}

